\title{
Analysis of Boyer's Academic Ecological View and its Practical Significance on the Basis of the Diverse Academic
}

\author{
Yun Zhou, Lin Tao, Yuping Cao \\ Yuxi Normal University, Yuxi, 653100, China
}

\begin{abstract}
Keywords: Boyer, Academic ecology; Multiple academic, Academic reflection, Practical significance
\end{abstract}

\begin{abstract}
Boyer is a famous American educator in the 20th century, Boyers education research emerging from the practice in the field of inquiry, by the academic reflection, it has reference significance for the development of China's college education. In the $90 \mathrm{~s}$, aimed at the American university academic ecological alienation of importance to scientific research and teaching ignore reality problem for the academic reflection, it will be a new academic ecology. This thesis aimed at Boyer academic thought, from the perspectives of multiple academic Boyer 's ecological view and its practical significance.
\end{abstract}

\section{Introduction}

Ernest Boyer (Ernest Boyer 1.) (1928-1995) is a famous contemporary American higher educator, devoted to the study of American education in colleges and universities. In the $90 \mathrm{~s}$, the key problems in the work of professor Boyer in view of the academic reflection, published the famous report, entitled "the focus of the academic reflection: professor" (Scholarship Reconsidered: the Priorities of the Professorates).The core content of the report, that is, to the United States higher education systematic research, and puts forward the concept of academic ecology. For more than 20 years, Boyer's view has positive influence on the higher education in the United States, and the education of higher education all over the world play an important guiding role. When we reflection Boyer academic research background, the study of Boyer's academic achievements, I think that it is important for China's higher education reform.

\section{Boyers academic ecology}

Higher education in the United States in a variety of forms, but with the popularity of higher education, it makes the orientation in the convergence. When Frank Rhodes at Cornell University in the United States to serve as President of the 18 years, the school management experience for many years, he had a new understanding of the education style of colleges and universities. In his view, the university education style simplification is bad for the future development of colleges and universities. On the style of education, some new university will deliberately follow established research university education mode, makes the university style similar to that of a single of the university education, the university academic ecological balance as a result.

University education is given priority to study, it is suit for some universities, but for most colleges and universities, has become an obstacle to the development of colleges and universities. Only to shape a good education environment of colleges and universities, to realize the value of education, but the current academic ecology, obviously makes the academic research and education in colleges and universities. The ecological environment, which is formed by the university will, in fact, research as to promote the development of "opportunities" (opportunity), and ignore the importance of education, it will lead to some universities teaching as to interfere with the development of the school "burden" (load) ${ }^{[1]}$.

Colleges and universities exist "heavy light education scientific research" is a major problem, which seeks to shape a academic environment, and it does not give enough attention to teaching. In particular, some colleges and universities to imitate the mode of the established colleges and universities, it was unaware of the established colleges and universities has experienced years of 
history, which has formed a strong academic atmosphere, and established colleges and universities has a strong culture and strong campus academic atmosphere, make academic activities and education combined. Based on the investigation to the American colleges and universities, he got a new academic ecology, and published in 1990 entitled "the academic reflection: professor work in key areas of study, put forward his views to create a new academic ecology, he thought the university education is not only guide students to study, but also to explore the related issues from four aspects: to explore the academic (the scholarship of discovery), for a wide variety of research conducted in the form of inquiry; Integration of academic scholarship of integration), will explore information for effective integration, form an organic whole; Application of academic scholarship of application), is the integration, processing of information in the field of application verification; Teaching academic scholarship of would), it is authenticated information better educated, through to carry out teaching activities, it will be knowledge popularization.

No teaching support, it is difficult for academic development, it will not live on academic research achievements. To the academic to the new location, combining academic and education, scientific research in colleges and universities functions, functions of personnel training and social service intelligent integration, mutual penetration, promote academic research and social practice in academic boundary is expanding, not only enriched the contents of academic research, and also established new academic view, namely, to explore the academic, integration of academic and application of academic, teaching in equal status, live in harmony with each other, in order to maintain academic ecosystem benign run ${ }^{[2]}$.

\section{The establishment of a pluralistic academic ecosystem}

In the $80 \mathrm{~s}$, America's social and economic rapid development, rapid rising of science and technology university recruitment of students scale expands unceasingly, it leads to the neglect of education function and one-sided emphasis on scientific research. With a variety of scientific and technological achievements have been used in the production and living areas, improve scientific research status, with the academic activities of colleges and universities increasingly frequent, one of the important reason is that by raising the scientific research in colleges and universities, can rely on the scientific research achievements obtained apply for government funding, at the same time also can gain higher social reputation. Teachers use of time and energy for scientific research of colleges and universities, and under great pressure, leads to college teachers ignore the quality of teaching, and also affect the service function of colleges and universities. There is this kind of phenomenon the reason is that university teachers have no correct understanding the connotation of academic research, so without considering the teaching and academic research complement each other, from multiple disciplines of education, it is quite necessary for the integrated use of and application.

After the Second World War, American colleges and universities has entered the stage of popularization. Colleges and universities of its own with no clear positioning, schools are classified, each work in multi-level, but popularization of college education school in order to improve the visibility and credibility and cause the academic ecological balance. In the diversified social environment, higher education should fully meet the demand of students and to broaden the academic field of vision, make every student can duly accept education; the academic focus should satisfy various forms of academic research activities. The establishment of a diversified academic ecosystem, the diversity of academic, academic focus of flexibility, requires universities to school-running ideas clearly, all the work of colleges and universities around the school idea, make the form of education scientific research of synchronization with the development of the school[3].

To build up diversified academic ecological system, to highlight the characteristics of colleges and universities. Colleges and universities according to its own characteristics for teachers and discipline advantages choose the school focus, or academic research, or teaching, or which are integrated and applied to the practice in the field of knowledge. No matter choose any kind of education form, from the perspective of characteristics of running a school, school education characteristics, it is not only to establish between academic ecosystem, between different departments of colleges and universities can also according to the need to diversify its campus academic. Different colleges, different 
specialties, and form their own characteristics, not only can realize the complementary advantages with other colleges and universities, but also points the way for the development of colleges and universities.

\section{Boyer academic reflection on the American colleges and universities}

\section{Localization of the connotation of "academic" by Boyer}

Boyer argues that teachers' academic research work includes four aspects, integration, application and teaching.

Explore academic is core part of academic research, to develop interest in knowledge study, and give appropriate protection, thought that the exploration of new knowledge foundation.

Comprehensive academic, is to establish connections between different disciplines of knowledge, with the method of heuristic education for non-professional person to carry out the education. Comprehensive academic research focuses on interdisciplinary research, professional research field gradually marginalized, found that academic overlap, and enlarge the knowledge mode, different research results is blended in among them, promote systematic integration between each other.

Application of academic is derived from the academic life. Boyer argues that academic performance is to serve the society, require that the professional knowledge and service activities, in the form of professional activities, and improve the professionalism of the service and seriousness.

Academic teaching is teaching as a way of maintaining knowledge continuity. Boyer argues that the purpose of teaching is not only imparted knowledge, but to transform knowledge, and knowledge to expand application field. Students through a variety of learning activities to the discussion of knowledge, it has been questioned, professor will also get new inspiration.

\section{Reasonable transfer of academic focus}

In order to avoid the monotonicity of the university teachers' work and repeatability, you need to redefine the concept of "academic". According to the traditional view, is the main task of the university teachers' teaching, help students to establish the knowledge base, and less involved in to the application of knowledge. Teachers have potential ability, only the appropriate environment can give full play to come out. In particular, some teachers in the field of scientific research, teaching will also be interested in, you need to create opportunities for them to carry out the teaching. Boyer, points out that the teacher's career, need to experience different research stage, to face all kinds of special tasks. If teachers take on too heavy work task, will affect the academic research. In addition, the academic research field is different, its productivity condition also exists difference [4].For example, the physical and chemical research achievement is much more research group at the young stage, history, philosophy, psychology and the research achievements are mostly middle-aged academic achievement is higher. Through the understanding of the career development path, the establishment of academic evaluation system and incentive system, encourage college teachers in different stages of study transfer academic interest, beneficial to teachers to connect different professional fields, so that the effective connection of different professional knowledge in academic research, which makes teachers in different academic study phase shift key, in order to make teachers maintain the vitality of academic research.

\section{The practical significance of academic ecological view}

\section{Teaching academic development for teaching and learning}

Lee Shulman (Lee Shulman) is Boyer's successor, his academic ecology of Boyer inherited at the same time, also in the practice of Boyer theory, it has played a role, and the teaching of academic development become the teaching and learning, so far, teaching and learning of teachers' academic culture is more and more colleges and universities, and actively participate in teaching and learning in action, make the theory root of colleges and universities in the United States. Some scholars believe that the past education problems in the study, only a few academic backbone, now, every ordinary teachers can be involved in the field of academic research, the whole academic course teaching and students' quality in colleges and universities hold attention. Of university teaching, a professor at the 
education seriously at the same time, also actively involved in the teaching and learning literature, further exploration, in teaching practice constantly improve[5].

\section{Innovation the learning style of undergraduate learning}

Since the $90 \mathrm{~s}$, some colleges and universities have carried out the research learning in undergraduate teaching, breaking the traditional undergraduate study way, to create a basis for undergraduates into inquiry learning conditions. In the process of undergraduate education in colleges and universities in the United States, the inquiry learning through among them, the undergraduates have the opportunity to participate in academic research activities. Colleges and universities in the United States, according to the investigation data shows, more than $80 \%$ for undergraduate students in colleges and universities set up the academic seminar, established by the $46.8 \%$ of the college academic seminar for experienced old teacher. More than $70 \%$ of colleges and universities set opportunities for learning groups, to facilitate the learning teaching workshop are in a planned way.

\section{Expand the connotation of doctoral education}

American colleges and universities of doctoral education paid more attention to the doctoral education system, and is considered a "gold standard" system and by the rest of the world university doctoral education institutions to follow suit. In the $80 \mathrm{~s}$, America's Labor market presents the diversified development trend, the doctoral education simplification prevented Dr. Talent cultivation by academic mission, and not to lay a good foundation for their future career. Boyer for doctoral education put forward its own views, think to make the doctoral research field expanding, to redefine the concept of "academic", graduate school, it is not only the academic research, including knowledge in the field of application of penetration, and to carry out the teaching according to academic research. Only according to the cultivation, social demand has pointed out to ensure that personnel with high sensitivity to social demand, and constantly adjust their own learning content and learning style. Since the $90 \mathrm{~s}$, doctoral education institutions in the United States were in the course of development of doctoral education, doctoral student academic research and be combined with the demand of social economic development, it has changed the simplification of doctoral education mode, encourage doctoral student to dynamic changes in the talent market has stronger adaptability.

\section{Conclusion}

To sum up, Boyer multiple academic thought it is the theoretical value of the research, according to a more practical significance. Boyer, according to the education of the university ", "heavy academic teaching, from the perspective of academic research on teaching study and a new theoretical perspective on the relationship of the scientific research and teaching. Boyer put forward, the university academic research is divided into four, integration, application and teaching. Four academic depended on each other, formed the academic ecological system. Boyer in theory as the support and reflect on the teaching and laid a theoretical basis for education development of colleges and universities.

\section{Acknowledgments}

This article is part of the results of scientific research fund project in Yunnan province education department in 2015, Which name is Based on the Perspective of Self-Efficacy Frontier Minority Areas of Normal Colleges and Universities' Boyer Type English Teachers' Training Mode Study. (Item number 2015C082Y).

\section{References}

[1] Li Huan. The research and enlightenment of Boyer teaching academic. University of Henan,2010.

[2] Li Haiyu. Theory of Boyer of American university academic reflection and its reference significance on our country's higher education. Journal of Jiaozuo university,2013(04):97-100. 
[3] Zhou Jinfeng. The research under the academic thinking of education "outstanding engineers training plan" of Boyer. Jilin university,2013.

[4] Ma Xianglian. Reconstruction of university teachers "teaching responsibility consciousness under teaching academic perspective. Journal of continuing education research,2010(12):60.

[5] Ren Weining, Fan Tongshun, Yang Bing. The teachers performance evaluation which base on the academic view of local college. Journal of human resource management,2011(11):91. 